\title{
O LUTO NAS CRÔNICAS DE FABRÍCIO CARPINEJAR
}

Rebeca Soares de Lima ${ }^{1}$

RESUMO: A crônica, como gênero literário, vem se firmando cada vez mais nos jornais escritos e televisionados, revistas ou ainda por meio da publicação em livros. Por em alguns casos poder apresentar linguagem coloquial, com temas que podem estar relacionados a notícias ou a assuntos cotidianos, faz com que os leitores desse estilo se engajem numa leitura que, a primeira vista, parece despretensiosa. É assim que muitas crônicas de Fabrício Carpinejar se iniciam em Me ajude a chorar (2014). Pretende-se analisar como o luto é explorado ao longo do livro; explorando os diferentes e possíveis ângulos que as crônicas apresentam a dor do luto, seja pela perda dos genitores ou pela perda de relações amorosas. Para abarcar conceitos como luto, usar-se-á a psicanálise freudiana. Expondo assim, como uma das percepções, que a vida pode ser encarada como um ciclo, numa constante busca, com ganhos e perdas, vinculações e desvinculações.

PALAVRAS-CHAVE: crônica, luto, perda, psicanálise, Fabrício Carpinejar.

ABSTRACT: Chronic, as a literary genre, has been steadily increasing in newspapers written and televised, magazines or even through publication in books. Because in some cases it can present colloquial language, with themes that may be related to news or everyday affairs, it makes readers of this style engage in a reading that at first glance seems unpretentious. This is how many chronicles of Fabricio Carpinejar begin in Help me to cry (2014). It is intended to analyze how mourning is explored throughout the book; exploring the different and possible angles that the chronicles present the pain of mourning, either by the loss of the parents or the loss of love relationships. To encompass concepts such as mourning, Freudian psychoanalysis will be used. Thus, as one of the perceptions, life can be seen as a cycle, in a constant search, with gains and losses, entailments and disengagement.

KEYWORDS: chronic, mourning, loss, psychoanalysis, Fabrício Carpinejar.

\section{CONSIDERAÇÕES INICIAIS}

O luto, mais do que se pode imaginar, faz-se presente em muitos momentos da vida e é fato que a essa palavra associa-se outra, tão forte quanto ela, a morte. O que há na morte que pode causar tanto temor ou medo? O que há na morte, da qual ninguém escapa, mesmo depois de tantos séculos de história da humanidade, que ainda seja temida?

Ao se debruçar sobre esses questionamentos, pode-se perceber que o conceito de morte está para além de deixar de viver, de respirar, mas pode ser encarado também como perda de possibilidades, quaisquer que sejam elas. Garantindo que haja um ponto final. Pesado e certo. $\mathrm{O}$ luto é, portanto, neste caso, o nome dado à dor da perda de um objeto ${ }^{2}$ de amor, um objeto no qual se investiu, que ao perdê-lo, perde-se também toda a energia, o vínculo e a ligação criada entre esse objeto e o indivíduo.

Partindo dessa premissa, o luto está em inúmeros lugares, não só na morte enquanto corpo, mas na perda de sentimentos, de lugares, de pessoas, em outras palavras, está no

\footnotetext{
1 Mestre em Literatura pela Universidade do Estado do Amazonas. Professor da SEDUC-AM (Secretaria de Educação) E-mail: rebbeccalima@hotmail.com

${ }^{2}$ Alvo para o qual se destina libido, energia, que Freud (2014, p.437) apresenta como energia sexual em "O desenvolvimento da libido e as organizações sexuais".
} 
desligamento com o objeto de amor, que pode acontecer de forma abrupta ou não. Para Jorge (2010, p.149), "vivemos numa homeostase psíquica ou ao menos numa tentativa de manter esse equilíbrio, quando algo abala essa homeostase, um trabalho se inicia, o luto”. Para Freud pela leitura de Jorge (2010, p.150), o isolamento se faz necessário, pois "a energia só suporta um fator, viver socialmente ou recompor o equilíbrio". É em virtude disso, que o isolamento é tão característico de quem está enlutado.

Partindo dessa premissa, o conjunto de crônicas que aqui se analisa, do autor Fabrício Carpinejar, no livro Ajude-me a chorar (2014), apresentará constantemente a perda de algum laço afetivo ou de pessoas. A entrada desse assunto nas crônicas se faz de modo sutil e até despretensioso. Então, associamos a essa forma de iniciar com temas cotidianos a assuntos mais profundos o método que rege o fazer psicanalítico por meio da clínica fundada por Sigmund Freud (1996, p.79): a associação livre.

O silêncio, o vazio, o papel em branco podem fazem emergir do homem conteúdos que, muitas vezes, são rejeitados, negados, reprimidos. Freud (1996), ao perceber que havia um tom embaraçoso quando isso acontecia, deu fluxo livre a essa curiosa descoberta. O que emergia estava diretamente ligado às questões que o próprio sujeito trazia à análise, só que mais profundas, mais pessoais e, consequentemente, mais dolorosas e importantes. (FRIEDMAN, 2004) Mas emergia de onde? Onde que esses conteúdos eram reprimidos, jogados?

No inconsciente. Aqui a psicanálise funda toda sua análise, pois conteúdos trabalhados tinham que, necessariamente, vir a ser conscientes para se ter alguma eficácia. Por outro lado, o inconsciente não foi um conceito validado por muitos médicos que ouviam as palestras de Freud, foi considerado uma invenção, mas é dessa "invenção do inconsciente freudiano que dependeu o funcionamento prático de um dispositivo, que simplesmente põe em contato um que fala e outro que se dispõe a ouvir" (BARROS, 2012, p.22).

O que emerge desse inconsciente, tornando-se consciente, é o objetivo do método psicanalítico, é dali que virá o que realmente importa ser dito, ser verbalizado. Mas, o que tem o poeta com isso? Ora, ele, como todos os que se dispõem às artes - sejam elas musicais, visuais ou cênicas - de algum modo, parecem desenvolver um contato mais íntimo ou, ao menos, com menos resistências aos conteúdos que saltam do inconsciente.

Baseado no que já foi exposto até então, a crônica pode se utilizar da associação livre. Dito de outra forma, ela geralmente se inicia com algum tema que pode ser considerado banal, uma cena cotidiana, simples e comum e, essa informação, ao fim, é comparada com um assunto sério, importante; no caso do livro que se pretende analisar, doloroso. Parte-se do simples para o complexo em pouquíssimas linhas. A primeira informação é ponte para o que realmente se quer 
expor, é uma sucessão de associações livres que levam à origem da dor ou ao que se acredita que é a origem da dor.

\section{O REAL E A CRÔNICA}

"um poeta deve deixar vestígios da sua passagem, e não provas. Só os vestígios fazem sonhar."

(NASIO, 1999, p. 30)

Os assuntos ditos banais, muitas vezes, são retirados de algo que acontece no dia a dia, como uma notícia. A crônica nasceu entre as notícias como um lugar no jornal a ser preenchido, um espaço no qual não se sabia o que colocar, e se foi utilizando para escritas mais dinâmicas, para textos com caráter reflexível ou questionador. (NOGUEIRA, 2009)

Em vista disso, a crônica tem uma ligação direta com os textos jornalísticos e consequentemente com a história, ou ao menos com o que é publicado. Mas antes da ideia do jornal, principalmente as edições com cadernos, as crônicas podem ser vistas nos relatos de navegação, de guerras, de descobrimento, como forma de prestar contas a quem os enviou. Existiam crônicas de cunho jornalístico, mais impessoal, com mais dados a cerca do que se descobria, e as que a percepção do cronista era muito forte, deixando o documento mais subjetivo e a mercê do imaginário e, por que não, da fantasia de quem escrevia. (KAIMOTI, 2003)

A subjetividade pode gerar um problema, pois a percepção pode ser questionada, já que eram percebidos muitos tons míticos, doutrinários e lendários apresentados nas crônicas. Para Lacan, há três dimensões que compõe o homem: Imaginário, Simbólico e Real (JULIEN, 2010, p.49-53). O Imaginário é como uma espécie de lente pela qual vemos o Real, produzindo um Símbolo. Nosso imaginário é formado desde que nascemos, com percepções sensoriais, sentimentais, com lembranças e experiências, formando vários símbolos. De modo que, o Real é a dimensão nunca vista como realmente é, pois “é 'o que é estritamente impensável', é o impossível de ser simbolizado; o Real é, por excelência, o trauma, o que não é passível de ser assimilado pelo aparelho psíquico, o que não tem qualquer representação possível". (JORGE, 2010, p. 11)

Se o Real não é percebido em sua forma original, nenhum dos cronistas apresentará uma percepção igual nem mais fidedigna que a de qualquer outro. $\mathrm{O}$ que pode vir a diferir como essa percepção é apresentada e o que é ressaltado.

Pode-se usar essa teoria para entender melhor o porquê da crônica no jornal ser algo que difere grandemente da notícia, dispostas na mesma página do jornal. A escrita literária, 
artística, em essência, proporciona muito mais liberdade de estilo e conteúdo do que as jornalísticas. Por mais que o Real seja inalcançável a todos, o imaginário jornalístico está fincado no que se pode usar como comprovação, como justificativa, a escrita literária não necessita disso para viver.

Se o artista deixa fluir com mais facilidade assuntos delicados e reprimidos por outros, se sua escrita é livre de amarras morais, religiosas e até gramaticais, sua crônica, por exemplo, poderá expor conteúdos que muitos leitores não se permitiram pensar e/ou refletir. É aqui que a notícia entra como sintoma de uma comunidade, de uma necessidade coletiva, e o poeta, como o mais sensível, capta e dá voz por meio da escrita, pois, "num momento simbiótico, a história do lugar passa a ser também a história do indivíduo.” (MAGNI, 2009, p.93)

Carpinejar (2014), em Me ajude a chorar, utiliza-se dessa premissa em uma crônica referente ao incêndio na Boate Kiss no Rio Grande do Sul em 27 de Janeiro de 2013. Um desastre que chocou e comoveu o país. Enquanto todos os noticiários expunham motivos, problemas, fiscalização, história de familiares..., a crônica teve o foco em comportamentos que qualquer um faria para aproveitar melhor a noite e o show, proporcionando um processo de empatia e dor, como se o próprio leitor pudesse estar, sem esforço algum, na mesma situação das vítimas.

Morri porque tenho uma filha adolescente que demora a voltar para casa. Morri porque já entrei em uma boate pensando como sairia dali em caso de incêndio. Morri porque prefiro ficar perto do palco para ouvir melhor a banda. Morri porque já confundi a porta de banheiro com a de emergência. Morri porque já fui de algum jeito todos que morreram. Morri sufocado de excesso de morte; como acordar de novo? (CARPINEJAR, p.150, 151).

O acúmulo de mortes, de perdas que atingiram tantos pais, mães e irmãos, o que dizer? Nas últimas décadas têm sido cada vez mais perceptível uma cisão quanto aos tipos de jornalismo, uma que apresenta a notícia e outra que a explora, intituladas sensacionalistas. Perante a morte de "duzentos e quarenta e dois jovens sem o último beijo da mãe, do pai, dos irmãos" (CARPINEJAR, 2014 p.151), o eu narrador, que morre com cada pai e a cada vez que já fez o que muitos dos jovens fizeram naquela boate, muda o foco da notícia, deixando-a pessoal, provocando uma aproximação, sem julgamentos e sentenças, proporcionado um movimento empático.

Esse caráter é apresentado por Martins (1985, p. 3), como a crônica sendo "um gênero com muitos leitores no qual o cronista registra vertiginosamente a fisionomia e a alma de seu tempo". Alma e tempo que, nos últimos anos, por exemplo, têm uma vida noturna crescendo de 
forma vertiginosa nas grandes capitais, onde cada vez mais cedo jovens e adolescentes frequentam casas de show e bares, às vezes sob a forma de happy hours.

Daí se ressalta que esse tipo de escrita parece ter uma ligação com a atualidade, com o que é posto em vigência pelos meios de comunicação. A notícia é o exemplo da velocidade das informações transmitidas e, nos últimos anos, essa velocidade tem aumentado de forma exponencial. Entretanto, visto por outro ângulo, "a aceleração da informação trouxe ao ser humano o dilema de sua saturação, a crença no progresso favoreceu o individualismo e o advento do sujeito preocupado unicamente com o ganho e a acumulação.” (PINTO, p. 73, 2014)

Diante desse efeito, a crônica tem se apresentado como o texto com uma capacidade de sensibilizar quem a lê, como um retorno ao coletivo, ao sentimento empático, proporcionando a visão de que os mesmos problemas podem fazer-se presentes em pessoas distintas. Neste contexto, o moderno, o atual nos move em direções contrárias, num movimento de convergência e divergência, pois na medida em que se recebe informações de todos os lados, o tudo se torna nada, pois não há absorção. Berman (2007, p.24) corrobora esse aspecto, expondo que "a modernidade une a espécie humana. Porém, é uma unidade paradoxal, uma unidade de desunidade: ela nos despeja a todos num turbilhão de permanente desintegração e mudança, de luta e contradição, de ambiguidade e angústia."

\title{
A CRÔNICA E A (SUA) HISTÓRIA
}

\author{
"a crônica se apresenta como um meio dos mais \\ profícuos para se entender o mundo contemporâneo"
} (MAGNI, 2009, p.91).

A palavra crônica vem da palavra grega chronos, que significa tempo, remetendo-nos também ao deus grego. Em vista disso, é interessante perceber que ela já foi uma espécie de relato de viagem e atualmente, mesmo depois de tantos anos, o caráter de manter um contato com a atualidade, com a notícia, com o jornal ainda seja tão presente na contemporaneidade. É como se o cronista fosse uma espécie de "intérprete das mutações que dão nova fisionomia à sociedade" (MELO, 1985, p.115 apud KAIMOTI, 2003, p.19).

Esse caráter se fez presente nas crônicas de autores famosos, como Machado de Assis e Carlos Drummond de Andrade, que escreviam desde críticas ao sistema político vigente aos assuntos relacionados a fatos noticiados pelo mesmo jornal ao qual estavam vinculados. Por mais que a notícia apresente números, estatísticas e que se possa formular teorias baseadas nisso, compondo assim registros para a composição da própria história, ela "pela interpretação, 
pelo subjetivismo, pela comunicação, pela ideologia - é também uma ficcionalização do real" (SILVEIRA, 1992, p. 27 apud KAIMOTI, 2003, p.14).

O jornal, seja pela facilidade em adquirir, pelo baixo custo financeiro ou por ser uma prática tida como "normal”, percebeu-se que os leitores estavam mais abertos à leitura literária neste do que na compra de livros, pois "alguns leitores se sentiam intimidados pelos livros e preferiam não mantê-los em casa. O periódico, porém, era mais amigável. Apresenta-se como um amigo que só quer soprar uma palavra em seu ouvido.” (BURKE, 2003, p. 160 apud BARRETO, p.69, 2006)

Então, a literatura, por assim dizer, passou a adentrar as casas cariocas, por exemplo, de forma mais livre, seus leitores passaram a ser fieis à compra dos periódicos e os autores passaram a ter um emprego cada vez mais fixo, já que seus livros ainda não eram vendidos suficientemente para o seu sustento.

Não só o crescente sucesso das crônicas nos periódicos como o nome dos autores já conhecidos também contribuiu para que os clientes dos jornais tivessem um incentivo extra para o início da leitura. Ter pessoas com certa fama já instaurada interessa muito aos que administram uma empresa que trabalha com notícias, pois "poucas coisas conferem mais prestígio à imprensa democrática do que manter um elenco variado e respeitado de colunistas, gente que assume a primeira pessoa do singular para poder falar mais de perto ao leitor." (DAPIEVE, 2002, p.100 apud BARRETO, p.66, 2006).

Ter um contato próximo, ter no enredo assuntos já noticiados e ser impresso em jornal fez com que a crônica no Brasil tomasse um fôlego para se sustentar sozinha, o que fez com que, em alguns casos, saísse do jornal e migrasse para o livro. Por mais que o livro pudesse ser visto, no final do século XX, como um caráter elitista, e “as crônicas as que 'viajam sozinhas' e as que chegam mais 'distraidamente' ao leitor,' (BARRETO, p.69, 2006), esse quadro vem se modificando cada vez mais.

Com o início do século XXI, a internet proporcionou o questionamento de conceitos como tempo, distância e interatividade, fazendo com que haja uma maior facilidade na compra de livros, sejam impressos ou em e-books. Vale ressaltar que mesmo com uma quantidade extraordinária de textos disponíveis de forma gratuita, o livro impresso ainda permanece como preferível para muitos leitores. Bem, quando à crônica, ela passa a estar em outro lugar que não seja só no jornal, "verificamos meio espantados que a sua durabilidade pode ser maior do que ela própria pensava.” (CANDIDO, 1992, p. 14). Durabilidade essa que o jornal não possui, pois um dos aspectos do jornal é estar atual e poucas horas depois ser jogado fora. 
As crônicas dos últimos 10 anos têm tido um espaço maior nas editoras também por ser uma leitura dinâmica, rápida e com temas, na maioria das vezes, atrativos. Alguns autores contemporâneos se destacam como Luiz Fernando Veríssimo e Fabrício Carpinejar. Coutinho (1986, p.135) muito antes já havia percebido o processo de mudança e questiona: "Não será antes [a crônica] um gênero anfíbio que tanto pode viver na coluna de um jornal como na página de um livro?" Ousa-se acrescentar outro fator, pois ela passou a habitar em mais que os dois lugares, pois além do jornal impresso, há o jornal on-line, blogs, sites de relacionamentos como o facebook e, por fim, os livros.

Pode-se perceber assim, que pequenas narrativas a cerca de questões mais subjetivas vêm crescendo com uma velocidade relativamente grande. A crônica tem se apresentado como eficiente no que tange a provocar um senso de reflexão "sobre nossos sentimentos, afetos e emoções nas relações com nós mesmos e com os outros se tornou um recurso, ou capital relevante para o estabelecimento de relações bem-sucedidas nas esferas pública e privada." (MATTOS, 2010, p. 33)

\section{ME AJUDE A CHORAR}

"a resistência é sempre resistência contra a dor" (NASIO, 1999, p. 102)

Carpinejar (2014) reúne crônicas que, a primeira vista, parecem ser sobre relacionamentos amorosos que se romperam, acabaram. Contudo, com o "andar" da leitura, é perceptível que o choro, ressaltado no título do livro, não é causado somente quando um namoro ou casamento se finda, pode ser mais profundo do que se faz parecer. Parte-se dos vínculos atuais para o primeiro vínculo: com a mãe, com o chegar ao mundo, se é que se quer chegar.

Não se estabelece níveis de sofrimento ou importância, mas uma cronologia. As crônicas obedecem a ordem do hoje para o início da vida. A perda dos vínculos que acaba gerando, inevitavelmente, o luto, a dor de se desprender do objeto de amor cuidado e zelado por um período de tempo. Para se partir ou adentrar a outra fase ou relacionamento, por exemplo, é necessário que esse desligamento aconteça, que as dúvidas sejam sanadas ou entendidas conscientemente.

Carpinejar inicia o livro com a crônica Pai de meu pai, onde a troca de papeis é dolorida e necessária, pois ser o provedor de quem o proveu, proteger quem já o protegeu, perceber o trabalhador, o que mandava, o que ordenava, voltar a ser criança, indefeso e incapaz de se movimentar pela casa é um privilégio, pois "feliz do filho que é pai de seu pai antes da morte, e triste do filho que aparece somente no enterro e não se despede um pouco por dia" 
(CARPINEJAR, 2014, p. 15). Privilégio e tristeza é um prenúncio do fim, da morte iminente, porque há oportunidade de cuidar e agradecer.

Esse agradecimento é exemplificado por meio das barras instaladas pela casa para que aquele (o pai) não caia, “a barra é emblemática. A barra é simbólica. A barra é inaugurar um cotovelo das águas" (CARPINEJAR, 2014, p.14). O filho não pode deixar de ser segurança nem no ato de tomar banho, "um cotovelo das águas". Reconhecer a impossibilidade do pai de se colocar em pé é mais do que ser observador, é ser cuidadoso. Atitudes desse modo podem nos fazer refletir sobre o quão o pai foi eficaz na dedicação paterna, sendo lei, como o que barra o amor do filho para com a mãe, Édipo, instaurando a norma. (NASIO, 2007) Temos aqui um duplo, a barra de apoio e a que simboliza a lei, para a primeira existir, a segunda tem que acontecer necessariamente.

Para melhor expor, Nasio (2007, p.123) em seu livro Édipo: o complexo do qual nenhuma criança escapa, apresenta que é por meio do Édipo que o superego é firmado, pois, em suma, "a travessia do Édipo pode ser lida como o encontro de uma criança com as três figuras do pai - simbólico, real e imaginário: um pai que representa a Lei, outro que a faz ser respeitada e, finalmente, aquele, invejado e contestado, que detém o Poder.” Em outras palavras, pode-se pressupor na presente crônica um filho que passou pelo Édipo, um filho no qual o superego não permite abandonar o pai, um pai que instaurou a lei, permitindo que o filho transpusesse o desejo à moral.

O menino abandona os pais como objetos sexuais e os mantém como objetos de identificação. Uma vez que não pode mais tê-los como objetos de seu desejo, apropria-se deles como objetos do seu eu; na impossibilidade de tê-los, promete inconscientemente ser como eles - em suas ambições, fraquezas e ideais. [...] O resultado dessa passagem da sexualidade à moral é o designamos supereu e os sentimentos que o exprimem: pudor, sendo de intimidade, vergonha e delicadeza moral. (NASIO, 2007, p.40-41)

Seguindo nessa perspectiva de pai, temos na crônica Coragem na chuva um processo de identificação, onde havia uma atividade que era exclusiva do narrador (criança) e do pai: assistir a uma tempestade. Era um espetáculo particular, pois era o único momento que o pai era só seu, enquanto todos se trancavam e gritavam, eles estavam plenos, assistindo "o mundo acabar" em uma paz que só eles entendiam. "Ríamos de nossa coragem, enquanto os familiares gritavam em desespero para que a gente entrasse logo.” (CARPINEJAR, 2014, p.30)

Não só a identificação pode ser vista como a sexualidade sob a forma de escolha da parceira, que é produto também do Édipo, pois a voz do narrador deixa claro que a aprendizagem foi firmada naquele tempo, quando "meu pai me explicou, lá na minha criancice, 
que temos que procurar a parceira certa. Só dois passionais não cobram passos. [...] Não vão se atropelar porque partilham a mesma velocidade da ventania." (CARPINEJAR, 2014, p.31) Dito de outra forma, a vida a dois é feita por dois iguais e não opostos. É importante que haja identificação, pois a primeira rivalidade e posterior identidicação foi estabelecida no Édipo.

Expor sobre Édipo é de suma importância em virtude de os pais serem os primeiros a criarem vínculo com os filhos, a proporcionarem apego, a firmarem seu ego por meio do constante contato. Partindo dessa relação, os próximos vínculos criados terão a dos pais como parâmetro, seja para confirmar ou negar, e, exatamente por isso, a perda dos pais apresenta-se mais dolorosa e marcante.

Se a perda do pai, por exemplo, como alguém que esteve presente nos primeiros anos de vida - um período considerado delicado para a formação da personalidade - faz-se muito forte, causando, inevitavelmente, sofrimento na vida adulta, ao se tratar de uma criança, o impacto é maior e será carregado ao longo da vida que está por vir.

Percebe-se isso em Sempre tem espaço no amor, onde a separação dos pais muda a rotina do filho ainda criança, que, em detrimento disso, passa a arrumar as roupas desse pai na cama e conversar com elas, dizendo como foi seu dia e do quanto ele está triste com o que aconteceu. Ter a posse da roupa e a ausência da pessoa pode ser uma das causas do por que o narrador, desde então, passou a ocupar pouco espaço nos armários e a ceder o maior espaço para namoradas e esposas. "A ambição é deixar que minhas roupas casem também com as roupas delas, que nada fique isolado e casmurro, perdido e avulso" (CARPINEJAR, 2014, p.77), assim como foi na falta do pai.

São destinadas também duas crônicas para a mãe, em Ninar e Basta uma pitangueira. Nessas crônicas a mãe é exclusiva ao filho, em uma ela lhe leva para passear de carro, para que ele possa dormir mais facilmente, dizendo "você é meu filho preferido"; e noutra os dois bebem chimarrão na varanda no fim da tarde ao assistirem trabalhadores de uma construtora se divertirem como crianças ao subir nas árvores, lambuzando-se e dando risadas. "Não tem como: mãe é a memória antes da memória. É a nossa primeira amizade com o mundo" (CARPINEJAR, 2014, p.103-4).

\section{LUTO}

"em qualquer luto, raramente fica claro com exatidão o que foi perdido",

(PARKES, 1998, p. 24)

O sofrimento é algo difícil de ser escondido. Muitas crônicas expõem situações onde a dor é partilhada com amigos, com mães, pais e filhos. Para Nasio (2009 p.17), “o ser humano é aquele 
que tem a vontade irredutível, a necessidade imperiosa de comunicar-se com outro ser humano", esse precisar é muito saudável para que conteúdos internos sejam melhor entendidos.

Na crônica $O$ oceano e uma conchinha, o narrador, ao seguir o ensinamento de sua mãe em ajudar uma senhora, porque "não custa nada ser educado" (CARPINEJAR, 2014, p.20), depara-se com o sofrimento de uma senhora viúva que o agradeceu beijando-o na testa molhada. Ele, naquela hora, não queria carregar suas sacolas e sim seus olhos cansados.

Pode-se associar aqui ao título do livro, ajudar a chorar, apoio no sofrimento, carregando os olhos que tanto já chorou e, no fim, um fim já consciente, ela desejava apenas uma coisa antes que seu esposo morresse: dormir mais uma última vez de conchinha, "uma só noite com as pernas entrelaçadas, as cabeças encostadas para igual horizonte. [...] Só dormir de conchinha mais uma vez. Uma noite fora do hospital, do soro, do medo de morrer." (CARPINEJAR, 2014, p.22)

Mesmo diante de tantas possibilidades de aproveitar os últimos momentos, mesmo diante de todo o sofrimento (oceano), as pequenas coisas marcam e são mais aconchegantes (conchinha, eis outro duplo significado). O narrador percebe a dor daquela senhora, a dor que pulava de seus olhos, o prazer simples que desejava, de estar com o esposo fora do hospital, a dor da morte de um esposo, de um homem, de alguém que já foi amante, que semeou um sentimento que floresceu na esposa até sua doença e morte.

Da morte física passa-se à morte da relação conjugal. Em A última palavra, temos ressaltado a dor do homem que escreveu um cartão do tamanho de um cartaz com as melhores lembranças de seis anos de casamento. Com o término da relação, ele o destrói e ela contesta esse ato e volta em casa, reconstitui o cartaz, reconstitui a relação, colando pedaço a pedaço do que ainda restava do cartaz e deles, pois “o cartão sempre será a pétala que não murcha, mais importante do que o buquê é a memória do buquê." (CARPINEJAR, 2014, p.24)

A percepção exposta é somente a dele. O Real era o cartaz. Ele, "homem de poucas frases, que nunca escrevia" (CARPINEJAR, 2014, p.23) ao fazê-lo, vai de encontro a esse símbolo reforçado por toda sua vida. Rasgar o cartaz era a certeza de que não deveria ter negado o ciclo Escrever - não saber se expressar - não ser compreendido, rejeitado (Real-ImaginárioSimbólico). Ao mudar um fator da tríade, muda-se o resultado também. O final do casamento era definitivo, portanto, inútil manter e, agora, não se abrir a mais ninguém. Imaginário: não era uma pessoa com facilidade para se expressar, ao fazer, a relação acaba, gerando um símbolo: não se abrir a mais ninguém. Esse ciclo apresentado se quebra com a reação dela, que volta e cola todos os pedaços, reconhecendo seu esforço em se expressar e aceitando-o. 
E como continuação, tem-se $O$ amor depois do divórcio, retratando a volta dos casais que passaram por brigas em tribunais, nas ruas, nas casas de parentes e se reconciliam, "o par percebe que é melhor ser inexato do que inexistente" (CARPINEJAR, 2014, p.28). Definida a escolha de ter uma relação, vê-se também que nunca se retorna da mesma forma que um dia já foi, pois os dois já não são os mesmos, já que "no mesmo rio não há como entrar duas vezes" (SCHÜLER, 2007, p. 133) como já expunha Heráclito. "Quem era ciumento retorna equilibrado, quem era indiferente regressa atento" (CARPINEJAR, 2014, p.27).

Aqui podemos perceber também a mudança nos esquemas de Real-ImaginárioSimbólico. Com o retorno, a percepção do Real muda, ou seja, o imaginário é modificado com a separação, produzindo um novo símbolo: "viram que o príncipe se vestia mal, e o sapo coaxava bonito. [...] Não existe certo e errado, existe amor e ponto. O que soava como crítica antigamente passa a ser conselho." (CARPINEJAR, 2014, p.27) Percebe-se, em vista disso que o que acontece, de forma cada vez mais frequente, é que os casais "têm que inventar elos que os unam. E têm que redefini-los constantemente; têm que escolhê-los de novo infinitamente." (HEFEZ, 2013, p. 192)

Perante as dificuldades, diante da relação a dois, Hefez (2013, p. 171) no livro Homens no divã, expõe que em uma relação amorosa de longa duração "cabe a cada casal inventar suas próprias regras, estabelecer suas próprias hierarquias, organizar-se, conforme a interioridade e o desejo de cada um, e não mais pelo que a tradição transmite há gerações”. Colocar-se em detrimento dos pais, em detrimento do que sempre foi feito deve ser uma atividade a ser repetida para que possa haver comunicação mais eficiente.

Por outro lado, quando o relacionamento está em harmonia, ainda se tem a morte para separá-los, como em Carta para Cíntia Moscovich. Nessa crônica temos um casal que se depara com o câncer e a despedida se dá certa e dolorosa. A ligação expressa é quase simbiótica e atemporal: "não sei quando nos conhecemos, porque quando amamos toda nossa vida quer participar do primeiro encontro. Meu esquecimento da nossa origem é excesso de memória”. (CARPINEJAR, 2014, p.142)

Ora, "amar também é assumir o risco de se deixar ultrapassar, possuir, amputar de sua liberdade e de sua autonomia” (HEFEZ, 2013, p. 177). Não abrir uma porta é fechar outras, "ninguém entra numa escolha sem fechar a porta" (CARPINEJAR, 2014, p.143) e se pode perceber essa escolha realizada, porém, o desespero perante a morte também pode ser encarado como característico, principalmente quando se trata de pessoas com as quais há vínculo.

O luto se apresenta com algumas fases, para Parkes (1998, p. 24), o "entorpecimento, que é a primeira fase, dá lugar à saudade ou procura pelo outro, e estes dão lugar à 
desorganização e ao desespero, e é só depois da fase de desorganização que se dá a recuperação". Pode-se situar, nessa última crônica, a saudade: "ainda atravessaremos o último do ano com lentilhas. [...] ainda ainda ainda seremos uma risada serena" (CARPINEJAR, 2014, p.143), e a procura pelo outro, a esperança: "vamos passar por mais esta filhadaputice da vida" (CARPINEJAR, 2014, p.143)

\section{INSCRIÇÕES DA DOR}

"Somos o que ficamos depois de sofrer" (CARPINEJAR, 2014)

Todas as experiências deixam marcas, muitas delas não podem ser removidas, são negadas, revisitadas ou sofrem releituras, modificando a percepção dela. Carpinejar inicia algumas crônicas explorando a dor depois do luto, o que vem a modificar os comportamentos subsequentes, mudando o sujeito permanentemente.

Em Cachorro manco, a marca é visível e irreversível, o cachorro não tem uma pata. Além da perda de um membro, todos podem ver essa perda e a vida tem que ser adaptada à essa perda, "ele sofreu e não se tornou arredio. Sofreu e não deixou de oferecer o coto" (CARPINEJAR, 2014, p.33). A comparação entre o cachorro e os que já sofreram por amor é explícita, todos podem sofrer, mas nem todos se apresentam de forma tão eficaz no retorno de uma dor quanto um cachorro manco. Ele é "harmonioso na falta, nos diz que não dependemos de equilíbrio, e sim de um lugar para ir" (CARPINEJAR, 2014, p.34).

A psicanálise expõe que a falta é o que move o desejo, é o que faz o sujeito se movimentar, o desejo caminha em busca da satisfação, que nunca é completa, nunca chega a completude. A busca do objeto de desejo que se modifica eternamente é intitulada por Lacan de objeto $a$, já que nem se nomear é possível, pois ele pula de objeto em objeto. "De objeto em objeto, o desejo desliza como que uma série interminável, numa satisfação sempre adiada e nunca atingida". (GARCIA-ROZA, 1985, p.139) O cachorro parece saber que a falta é perene, continuar desejando é o caminho, é onde se deve ir.

Perante algumas dessas faltas, o sujeito pode ter a ajuda de outros, no caso das presentes crônicas, a família se faz presente constantemente, como em $O$ impossível é sobrenome do medo, onde o eu narrativo expõe várias situações desde a infância até sua vida adulta. 
escrever, mas a letra da minha mãe foi a escada para as histórias. Eu pensei que nunca teria uma namorada, mas o beijo veio distraído no recreio da segunda série. [...] Eu pensei que nunca teria filhos, eu pensei que nunca dividiria a casa com alguém, eu pensei que nunca seria dependente do olhar de uma mulher, eu pensei que nunca teria dinheiro, eu pensei que nunca seria feliz. (CARPINEJAR, 2014, p.39)

Pessoas como o avô, a mãe e o pai funcionaram como ego auxiliar, como apoio perante circunstâncias e atividades que o mesmo não conseguia realizar sozinho. Na medida que o amadurecimento do ego se apresenta, as dificuldades se mostram proporcionais, como ser dependente do olhar de uma mulher e ser feliz. É perceptível a presença de desejos que não estavam ao alcance e foram satisfeitos, e logo outros foram erguidos. O ciclo é infinito e "enquanto pertencermos a esse universo em que tudo assume mil e um sentidos, jamais chegaremos à plena satisfação do desejo, porque, daqui até a satisfação plena, estende-se um campo infinito, constituído de mil e um labirintos.” (NASIO, 1993, p. 38).

A procura do objeto a pode ser visto como sinônimo de inícios e términos, de satisfações passageiras. Partindo disso, ao se tratar de satisfação em um relacionamento amoroso, nem sempre esse término se dá de forma igualitária para quem está nessa relação. Assim é em Querido Caio Fernando de Abreu, uma carta onde são depositados questionamentos a cerca do sofrimento de quem esperava mais do relacionamento no qual se investiu, é um misto de indignação e tristeza, de luto e revolta: "como alguém afirma que nada muda da noite para o dia e esquece as noites que mudaram seus dias?” (CARPINEJAR, 2014, p.89)

As perguntas não parecem ser de cunho retórico, contudo, por mais que se queira alguma resposta, elas não são realizadas a quem deixou a relação a dois, mas a um que está de fora. É nítido que o relacionamento era percebido de forma distinta entre o eu que narra e a mulher de quem se fala. A percepção do Real pelo Imaginário se dá de forma diferente, pois para um o afeto liberta, para outro sufoca. "Se o afeto sufoca, me diz, o que liberta?" (CARPINEJAR, 2014, p.86).

Perguntas sem respostas, perguntas soltas no ar, destinadas a outros que não a quem realmente importa também aparecem em Voo 1965, única crônica com o eu narrador feminino. Ela, não nomeada, despede-se da mãe tardiamente, depois de um acidente aéreo. A voz da filha, que se vê como rebelde, isolando-se propositadamente, arrepende-se de todos os momentos desperdiçados e questiona: "por que ninguém cresce sem dor? Por que não se cresce na alegria? Parece que a alegria só nos torna infantis. Explica vai? Explica que estou ouvindo.” (CARPINEJAR, 2014, p.146) 
Para Hefez (2013, p. 119), "quando temos intimidade com alguém, somos capazes de ser, ao mesmo tempo, nós mesmos e o outro, sem perder a identidade”. O vínculo com a mãe e a perda dela faz com que se perceba o quanto há traços em comum com ela, o quanto o cuidado não foi valorizado, o quando se é parecido sem ser igual. Perceber a mãe presente, mãe ausente, mudar o Real, faz com que o imaginário também mude. Imaginário de mãe chata, careta, agora mãe desaparecida, mãe ausente, sem corpo, sem mãe.

Nossa casa é um cemitério, nem preciso sair daqui para visitá-la, mãe. Vejo você em qualquer canto. Um fantasma apareceria menos vezes do que você, mãe. Você é uma ausência. Mais do que um fantasma. Uma ausência. Não houve um corpo para enterrar, desapareceu. Sumiu de repente. Está em tudo e em nada. Não posso ouvir uma campainha, um interfone, sem desconfiar de um milagre, porra, um milagre, um erro de digitação de Deus. (CARPINEJAR, 2014, p. 146)

Para a teoria lacaniana, "a cura é uma demanda que parte da voz do sofredor, de alguém que sofre por seu próprio corpo ou por seu pensamento". (NASIO, 1999, p. 161) A cura pela palavra - palavra essa que deve ser pronunciada, externalizada, por mais que a pessoa a quem se dirija não possa ouvi-la, como no caso da presente crônica. Por meio do sofrimento é que a palavra vem à tona, podendo se manifestar pelo choro, uma forma de expressão da dor.

\section{CONSIDERAÇÕES FINAIS}

"morrer produz barulho, sei, mas e o barulho de viver? Não dá pra ouvir dai?"” (CARPINEJAR, 2014, p.83)

"Ninguém vem do nada nem de lugar nenhum. Os vínculos sociais não são forçosamente um nó corredio que estrangula ou uma rede que aprisiona. São também a estrutura à qual podemos nos agarrar para não cair.” (HEFEZ, 2013, p. 189) Essa definição de vínculos resume de forma eficaz Me ajude a chorar, pois na mesma proporção que os vínculos estabelecidos podem ser motivo de dor, de sofrimento, pode ser também o que mantém o próprio sujeito, o que o sustenta, o que provoca a possibilidade de estabelecer vinculações outras.

Expor problemas no relacionamento com os pais e com os cônjuges é algo que se percebe ao longo da história, seja essa literária ou não. Como a crônica se faz presente por seu texto rápido, de mais fácil acesso e com a linguagem acessível, tratar de temas como esses, arriscamo-nos, é ter leitores certos, é atingir a todos os que se propõem a ler, é fazer com que o leitor perceba o quanto perder algo é doloroso e o quanto ainda se pode valorizar o que se tem.

Carpinejar, ao longo das crônicas, expõe de forma clara o quanto se pode sofrer, o quanto se pode reerguer, mesmo diante das mais dolorosas situações, como a morte do pai, da 
mãe, o término de um casamento, de uma relação amorosa. A capacidade de se vincular, de desligar-se, sofrendo com esse processo, mas daí em questionar, em rever o passado, em perceber o quanto se fez, o quanto ainda se pode fazer, pois o sofrimento não é perpétuo. Para Mc Crae e Costa (1993, apud PARKES, 1998, p. 44), "pode ser confortador saber que os seres humanos são criaturas altamente adaptáveis e, a longo prazo, que a maioria é capaz de enfrentar até mesmo os acontecimentos que causam grande desorganização e sofrimento”.

\section{REFERÊNCIAS}

BARRETO, Ivana. As Realidades do Jornalismo Cultural no Brasil. Rio de Janeiro: Contemporânea, N7 | 2006.2.

BARROS, Romildo do Rêgo. Compulsões e obsessões: uma neurose de futuro. Rio de Janeiro: Civilização Brasileira, 2012.

BERMAN, Marshall. Tudo que é sólido desmancha no ar: a aventura da modernidade. Tradução de Carlos Felipe Moisés, Ana Maria L. Ioriatti. São Paulo: Companhia das Letras, p. 24-26, 2007.

CANDIDO, A. "A vida ao rés-do-chão". In: CANDIDO, A. [et al]. A crônica: o gênero, sua fixação e suas transformações no Brasil. Campinas: Editora da Unicamp; Rio de Janeiro: Fundação Casa de Rui Barbosa, 1992, p.1-9

CARPINEJAR, Fabrício. Me ajude a chorar. $5^{\mathrm{a}}$ ed - Rio de Janeiro: Bertrand Brasil, 2014.

COUTINHO, A. "Ensaio e crônica". In: (Dir.); COUTINHO, E. F. (Co-Dir.). A literatura no Brasil. Dir. Afrânio Coutinho; codir. Eduardo de Faria Coutinho. , v. 6, 4. ed. São Paulo: Global, 1997.

FREUD, Sigmund. Obras completas: conferências introdutórias. Vol. 13 (1916-1917) 1ª Ed. São Paulo: Companhia das Letras, 2014.

obras psicológicas completas, Rio de Janeiro: Imago, 1996.

A interpretação dos sonhos I. Vol. IV, (1900). Edição Standart brasileira das

FRIEDMAN, Howard. Teorias da personalidade: da teoria clássica à pesquisa moderna. São Paulo: Prentice Hall, 2004.

GARCIA-ROZA, Luiz Alfredo. Freud e o inconsciente. 2 ed. Rio de Janeiro: Zahar, 1985.

HEFEZ, Serge. Homens no divã. Tradução de Iraci Poleti, 1 ed. São Paulo: Benvirá, 2013.

JORGE, Marco Antonio Coutinho. Fundamentos da psicanálise de Freud a Lacan: a clínica da fantasia. Rio de Janeiro: Zahar, 2010.

JULIEN, Philippe. A psicanálise e o religioso: Freud, Jung, Lacan. Revisão técnica: Marco Antonio, Rio de Janeiro: Zahar, 2010. 
KAIMOTI, Ana Paula Macedo Cartapatti. A presença da literatura em Crônicas de fim do milênio de Antonio Callado. Dissertação de mestrado apresentada no Programa de Pósgraduação em Teoria da Literatura, na linha de pesquisa Poéticas da Identidade, Campus de São José do Rio Preto, 2003.

MAGNI, Carlos. A crônica por Luís Martins: dissolução das fronteiras entre jornalismo e literatura. Conexão - Comunicação e Cultura, UCS, Caxias do Sul, v. 8, n. 16, jul./dez. 2009. MARTINS, Dileta Silveira. O estudo da crônica. 1985 (Mimeo.)

MATTOS, Patrícia. As representações do "novo homem" e da "nova mulher": continuidade e/ou mudanças nas relações entre os gêneros na esfera íntima. Universidade Federal de São João Del Rei - Minas Gerais, 08 de agosto de 2010.

NASIO, J. D. Cinco Lições sobre a teoria de Jacques Lacan. Tradução: Vera Ribeiro. Rio de Janeiro: Jorge Zahar, 1993.

Zahar, 1999.

- Como trabalha um psicanalista? Tradução: Lucy Magalhães, Rio de Janeiro:

- Édipo: o complexo do qual nenhuma criança escapa. Tradução André Telles. Rio de Janeiro: Zahar, 2007.

- Meu corpo e suas imagens. Tradução André Telles, Rio de Janeiro: Zahar, 2009.

NOGUEIRA, Clara Miguel Asperti. "Crônica": a suave ironia bilaquiana na gazeta de notícias. UNESP - FCLAs - CEDAP, v.4, n.2, p. 198-216, jun. 2009.

PARKES, Colin Murray. Luto: estudos sobre a perda na vida adulta. $3^{\text {a }}$ Ed. São Paulo: Summus, 1998.

PINTO, Raquel Solange. Crônica e modernidade: configurações da cidade. Cadernos Cespuc, Belo Horizonte, número 24, 2014.

SCHÜLER, Donaldo. Heráclito e seu (dis)curso. Porto Alegre: L\&PM, 2007.

STARK, Andrea Carvalho. Literatura Longe das Gavetas. Artefactum - revista de estudos em linguagem e tecnologia, ano $2-\mathrm{n}^{\circ} 2-$ v. 2 março 2009.

TUZINO, Yolanda Maria Muniz. Crônica: uma Intersecção entre o Jornalismo e Literatura. Disponível em: www.bocc.ubi.pt., Acessado em 30 de Maio de 2015 às 16h. Universidade Estadual de Ponta Grossa, 2010.

Recebido em: 28/11/2017

Aprovado em: 03/03/2018

Publicado em: 01/07/2018 